Instrumentation and Controls Division

Measurement Science Section

CONF-97/125-17

\title{
EXTRAPOLATIONS TO CRITICAL FOR SYSTEMS WITH LARGE INHERENT SOURCES ${ }^{*}$
}

J. T. Mihalczo

M. S. Wyatt

Oak Ridge National Laboratory

P.O. Box 2008

Oak Ridge, Tennessee 37831-6004

To be presented at the

American Nuclear Society 1997 Winter Meeting

November 16-20, 1997

Albuquerque, New Mexico

WTe submitted manuscript has been authored by a contractor of the U.S.

Govenment under contract No. DE-AC05-96OR22464. Accordingly, the

U.S. Government retains a nonexclusive, royalty-free license to publish or

reproduce the published form of this contribution, or allow others to do so,

for U.S. Government purposes.
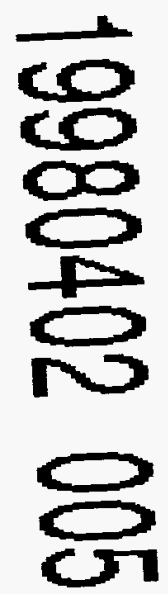

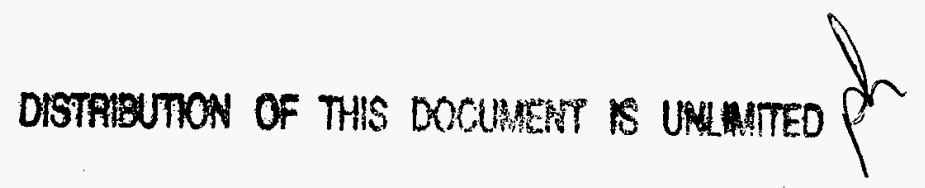

\footnotetext{
* Research sponsored by the U.S. Department of Energy and performed at Oak Ridge National Laboratory, managed by Lockheed Martin Energy Research Corp. for the U.S. Department of Energy under contract DE-AC05-96OR22464.
} 


\section{DISCLAIMER}

This report was prepared as an account of work sponsored by an agency of the United States Government. Neither the United States Government nor any agency thereof, nor any of their employees, make any warranty, express or implied, or assumes any legal liability or responsibility for the accuracy, completeness, or usefulness of any information, apparatus, product, or process disclosed, or represents that its use would not infringe privately owned rights. Reference herein to any specific commercial product, process, or service by trade name, trademark, manufacturer, or otherwise does not necessarily constitute or imply its endorsement, recommendation, or favoring by the United States Government or any agency thereof. The views and opinions of authors expressed herein do not necessarily state or reflect those of the United States Government or any agency thereof. 


\title{
EXTRAPOLATIONS TO CRITICAL FOR SYSTEMS \\ WITH LARGE INHERENT SOURCES
}

\author{
J. T. Mihalczo \\ Oak Ridge National Laboratory \\ P.O. Box 2008 \\ Oak Ridge, TN 37830-6004 \\ (423) $574-5577$
}

\section{INTRODUCTION}

An approach to delayed critical experiment was performed in 1981 at Pacific Northwest Laboratory with a cylindrical tank of plutonium-uranium nitrate solution. During this experiment, various methods to determine the critical height were used, including (1) extrapolation of the usual plot of inverse count rate vs height, which estimates the delayed critical height (DCH); (2) the inverse count rate vs height divided by count rate, which corrects somewhat for the change in inherent source size as the height changes; (3) ratio of spectral densities vs height, which extrapolates to DCH; (4) extrapolations of prompt neutron decay constant vs height, which extrapolates to the prompt critical height (PCH); and (5) inverse kinetics rod drop (IKRD) methods, which measure $\Delta \mathrm{k} / \mathrm{k} \beta$ very accurately for a particular solution height. The problem with some of the extrapolation methods is that the measured data are not linear with height, but, for lack of anything better, linear extrapolations are made. In addition to the measurements to determine the delayed critical height subcriticality measurements by the ${ }^{252} \mathrm{Cf}$ source driven frequency analysis method were performed for a variety of subcriticality heights. This paper describes how all these methods were applied to obtain the critical height of a cylindrical tank of plutonium nitrate solution and how the subcritical neutron multiplication factor was obtained. 


\section{FISSILE ASSEMBLY DESCRIPTION}

The high sensitivity of the calculations these frequency analysis parameters to nuclear data used in the calculation make them ideal for verification of calculational methods for criticality safety. In addition a variety of measured parameters are presented that can be calculated by Monte Carlo neutron transport. All of these parameters are related to $\Delta \mathrm{k} / \mathrm{K}$ to same power and are useful for verification of calculational methods for criticality safety. The fissile solution is contained in a 35.54-cm-OD tank with wall thickness of $0.160 \mathrm{~cm}$ and a bottom thickness of $0.952 \mathrm{~cm}$. The experiments were performed in this tank with varying solution heights and the also in the same tank with a central (on axis) Zircaloy pipe with an OD of $3.15 \mathrm{~cm}$, ID of $2.78 \mathrm{~cm}$, and bottom thickness of $0.635 \mathrm{~cm}$, with the bottom of the Zircaloy pipe $1.59 \mathrm{~cm}$ up from the bottom

of the tank. This pipe was used to locate a Cf source on the axis of the cylindrical tank. This tank was located inside a square enclosure. The concentration of plutonium in the fissile solution was $280 \mathrm{~g} / \mathrm{L}$, and that for uranium was $180 \mathrm{~g} / \mathrm{L}$ with free acid normality of 2.8 and a specific gravity of $1.754 \mathrm{~g} / \mathrm{cm}^{3}$. The uranium and plutonium isotopes in weight percent are given in Table 1.

For the experiments with the tank without the axial pipe the solution height was varied from $\underline{7.06}$ to $\underline{20.9} \mathrm{~cm}$ and this variation for the experiments with the axial pipe in the tank was $\underline{6}$ to $\underline{23.89} \mathrm{~cm}$.

\section{Cf SOURCES AND DETECTORS}

The $\mathrm{Cf}$ source used for the frequency analyses were of $6.29 \times 10^{6}$ and $2.61 \times 10^{6}$ fissions per sec. The discrimination thresholds the electronics of the ionization chamber containing the 
${ }^{252} \mathrm{Cf}$ were set such that 4.06 and $2.04 \times 10^{6}$ fissions per sec were counted and served as input to the frequency analysis.

Some of the better extrapolations to critical for the experiment without the central tube are plotted in Fig. 1, and the results of all the extrapolations are given in Table 1. The results produce a variety of critical height extrapolations. The extrapolations were performed linearly to obtain the height. The variations in critical height are $\sim 1 \%$. The most linear parameter with height is the ratio of spectral densities, and this provides the best parameters for extrapolation to critical. From the extrapolation of the prompt neutron decay constant to $\mathrm{PCH}$ and the ratio of spectral densities to $\mathrm{DCH}$, the change in height associated with plus one dollar in reactivity is $1.02 \mathrm{~cm}$.

To avoid the difficulties of extrapolating to delayed criticality, IKRD experiments can be performed close to critical to obtain the subcritical reactivity in units of dollars $(\Delta \mathrm{k} / \mathrm{k} \beta)$ using relative delayed neutron yields and decay constants. With values of the effective delayed neutron fraction, these results can be converted to subcriticality in units of $\Delta \mathrm{k} / \mathrm{k}$, which can be compared with calculations directly. 
TABLE 1: EXTRAPOLATED CRITICAL HEIGHTS FOR PLUTONIUM-URANIUM SOLUTION IN A 35.54-CM-OD CYLINDRICAL TANK WITHOUT REFLECTION

\begin{tabular}{|c|c|c|}
\hline Extrapolation Method & Source and Location & $\begin{array}{l}\text { Height }^{\mathrm{a}} \\
(\mathrm{cm})\end{array}$ \\
\hline Spectral Densities & Radial & $\mathrm{DCH}=56.64$ \\
\hline Inverse Count Rate $\left(\mathrm{CR}^{-1}\right)$ & Radial & $\mathrm{DCH}=56.10$ \\
\hline $\begin{array}{l}\text { Prompt Neutron Decay } \\
\text { Constant }\end{array}$ & Radial & $\mathrm{PCH}=57.66$ \\
\hline Inverse Count Rate & None & $\mathrm{DCH}=56.13$ \\
\hline Height/CR & None & $\mathrm{DCH}=57.4$ \\
\hline
\end{tabular}



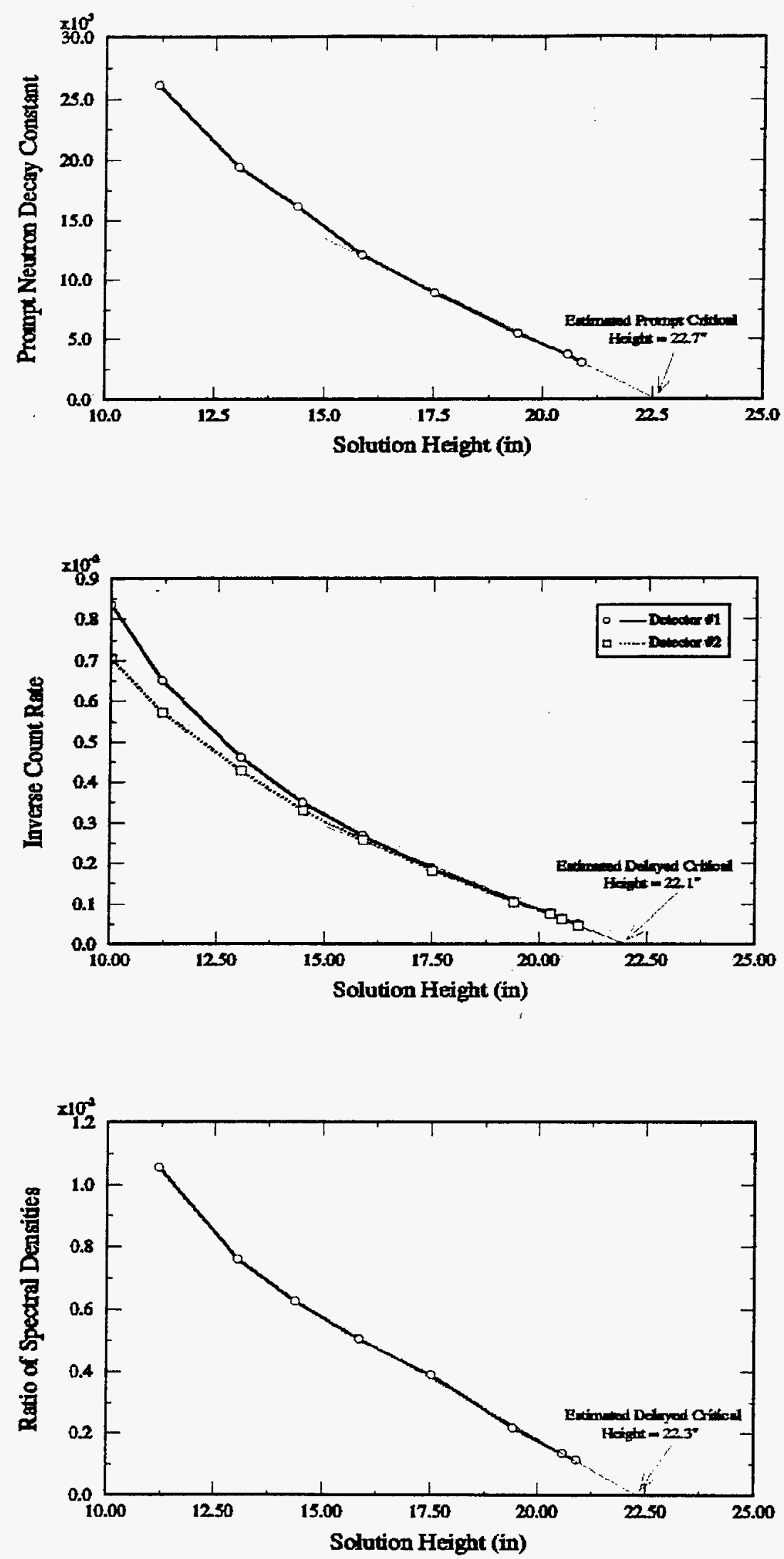

Fig. 1. Extrapolation of Some of the Measured Parameters to Obtain the Critical Heights for the Cylindrical Tank Without the Central Pipe 


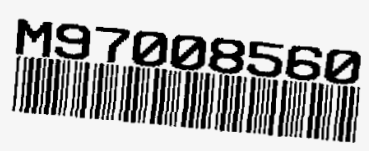

Report Number (14) CONF - $971125-17$

Publ. Date (11) $\frac{199707}{\text { Sponsor Code (18) }} \frac{\text { DOE }}{U C-900, D O E / E R}$
UC Category (19) 